\title{
Using the calculation method for low-melting clay assessment
}

\author{
Natalia Chumachenko, ${ }^{1, *}$, Vladimir Turnikov ${ }^{1}$, and Vladimir Kuzmin ${ }^{1}$ \\ ${ }^{1}$ Samara State Technical University, Academy of Architecture and Civil Engineering, \\ Molodogvardeyskaya St., 194, Samara, 443001, Russia
}

\begin{abstract}
Low-melting polymineral clays are widely used in building ceramics production. The properties of ceramic products depend on many factors. The paper describes properties of low-melting clay from Belebey deposit, Bashkiria. Using mathematical statistics methods, researchers make statistical analysis of grain size composition of clay raw material on Belebey brick factory and also analyze amount of sand additives and mixing moisture content. The study of general and technological properties of clay raw materials, and materials obtained from this raw material, was carried out in accordance with existing regulations using chemical, differentialthermal and non-standard methods. According to chemical analysis, nonstandard assessment of clay raw materials was carried out by means of computer program "Assessment", developed at the Department of Building Materials Production and Engineering Structures. The method of calculating quantity and composition of melted material, formed in ceramic masses during firing, using known diagrams of aluminosilicate systems state is used. The assessment made it possible to determine maximum firing temperature and firing range and additives improving clinker formation. The studies show that calculation indicators are consistent with experimental data. They can be used for quick assessment of raw materials properties when changing its composition, and in adjustment of technological parameters of production.
\end{abstract}

\section{Introduction}

A significant amount of ceramic bricks in the Belebey district in Bashkiria is produced at the Belebey brick factory. It was put into operation in 1997 and produces products on the technological line of the German company "Keller". The design capacity of the factory is 30 million pieces of conventional brick per year. In spite of modern production, in the output products there are such types of defects as "blisters" and drying cracks [2-3]. In addition to these defects, the brick produced has unstable strength characteristics. To develop measures that guarantee the production of ceramic bricks without the defects mentioned, it was necessary to find out their formation reasons. For this purpose, raw materials and production technology have been studied.

\footnotetext{
* Corresponding author: uvarovang@mail.ru
} 


\section{Methods and materials}

The factory uses the clay from Belebey deposit, which is located at a distance of $6 \mathrm{~km}$ from the factory. The deposit was explored in 1952-1953 by "Geolstromtrestom."

The useful area is represented by clay loam mantle, whose thickness equals to $9.08 \mathrm{~m}$. Clay loams lie under the factory layer (thickness $0.30-0.80 \mathrm{~m}$ ).

According to grain size composition, clay material refers to heavy differences. The reserves are approved by categories: A2 - 1853 thousand $\mathrm{m}^{3} ; \mathrm{B}-1388$ thousand $\mathrm{m}^{3}$. Approved reserves of the field are sufficient for 49 years factory operating (when the factory is loaded to full capacity). The explored part of the deposit covers an area of 17 hectares. Hydrogeological and mining-geological conditions are favorable for exploitation. There are prospects for expanding quarry boundaries up to 40 hectares. The average thickness of the useful layer is $7.5 \mathrm{~m}$, and the maximum thickness is $16 \mathrm{~m} \mathrm{[1]}$.

Sand of the Kabakovo field is used as a thinning agent. The deposit is located at a distance of $244 \mathrm{~km}$ from the factory. Approved reserves amount to 4 thousand $\mathrm{m}^{3}$. The average sand volume consumed per month is $800 \mathrm{~m}^{3}$.

The initial properties of clay raw materials of the quarry, the recommended composition of the furnace charge for a represented sample, and the technology foundations were determined by the German firm "Keller". The composition recommended for production: Belebey field clay $-85 \%$, sand - $15 \%$.

Ceramic bricks production is carried out in a plastic way. The products drying time is 72 hours.

Firing conditions: heating rate $-180^{\circ} \mathrm{C} / \mathrm{h}$; firing temperature is $1020-1050^{\circ} \mathrm{C}$; holding time at the maximum temperature is 3 hours; the cooling rate in the zone of polymorphic quartz transformations is $25-30^{\circ} \mathrm{C} / \mathrm{h}$. The firing time is 42 hours.

The study of the general and technological properties of clay raw materials of the Belebey deposit, as well as ceramic materials obtained from this raw material, was carried out in accordance with the current standards and with the use of subtle methods of investigation: chemical, and differential-thermal, and non-standard methods [4, 5].

Considering the fact that the brick produced at the factory has unstable strength characteristics, and the presence of cracks gives a large percentage of rejects of finished products, statistical processing of the data accumulated in the brick factory laboratory from April 4, 1998 to April 30, 1999 was carried out [6, 7 ].

According to the chemical analysis, a non-standard assessment of clay raw materials was carried out with the help of computer program "Assessment", developed at the Department of the Production of Building Materials and Engineering Structures, "Samara State Technical University" [9, 10].

\section{Results}

The clay from Belebey deposit is homogeneous, dark brown in color, thin-layered, fractured, crumbly, partly ferruginous in fractures. Career humidity is $19.5 \%$. The mineralogical composition of clay is of a polymineral composition. The amount of watersoluble compounds is very low and equals to $0.25 \%$. The main type of water-soluble compounds is calcium sulphate.

Raw materials in accordance to All Union State Standart classification belongs to the following groups: according to the content of $\mathrm{Al}_{2} \mathrm{O}_{3}$ - to the group of acidic; according to the content of coloring oxides - to a group with a high content of coloring oxides; according to the content water-soluble salts - to low content group; according to the plasticity - to the moderately plastic group; according to the fire resistance - to a group of low melting clays; on the content of finely dispersed fractions - to low-dispersed fractions group; by the 
number of coarse-grained additives - to low content group; by the size of the additives - to a group with small and medium additives; by the type of additives - to a group with carbonate additives; according to the content of free quartz - to a group with an average content.

The coarse-grained additives composition is dominated by carbonate additives. Their content from the total number is more than $80 \%$. The presence of carbonate additives was recorded by the results of their reaction with hydrochloric acid, "boiling" being observed. Despite the large additives low content; the presence of limestone grains is a sign indicating the possibility of "blisters" formation and the subsequent destruction of products while moistening.

Using mathematical statistics methods statistical analysis of raw material clay composition and some technological parameters (the amount of sand additive, molding moisture), products appearance (the presence of cracks or their absence), and the strength data are processed. The results are shown in Figure 1.

Size grain composition
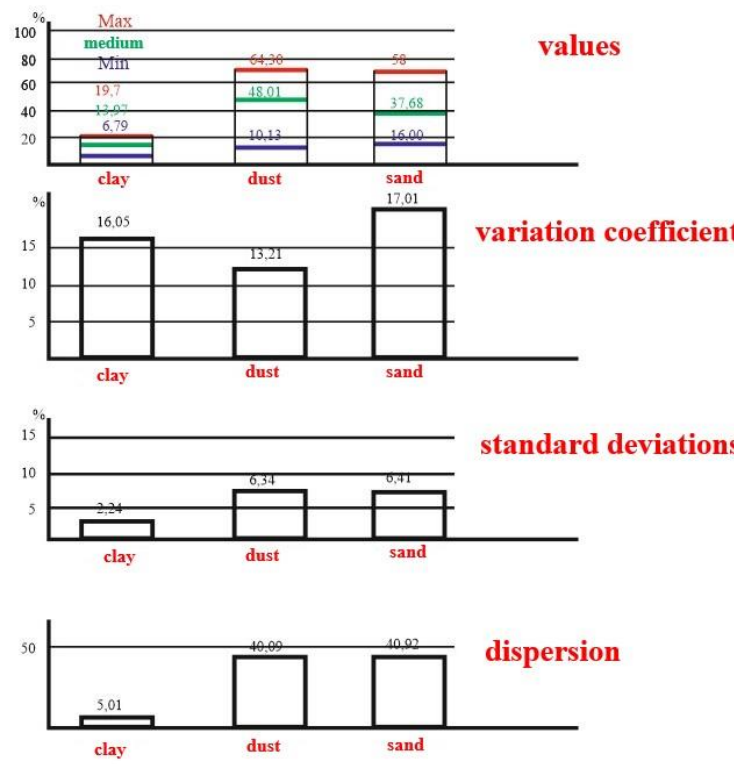

Technological parameters
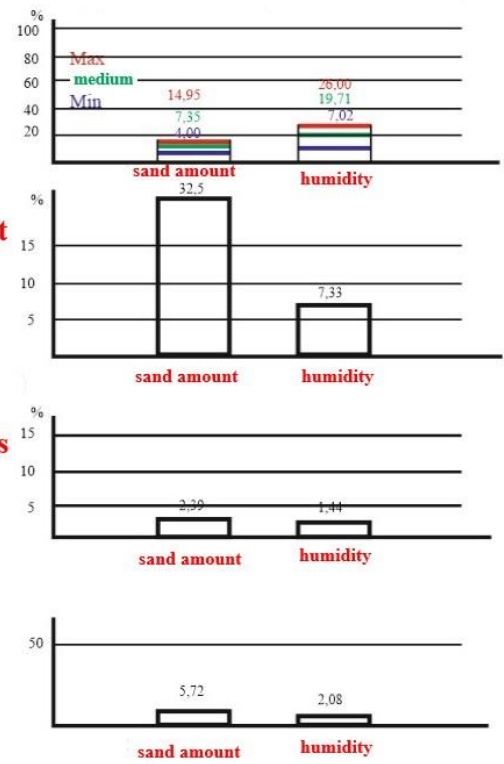

Fig. 1. Statistical analysis of the grain size composition of raw material and some technological parameters on the products appearance

The graph of melt formation dynamics, constructed by virtue of the calculated characteristics, is shown in Figure 2.

As can be seen in Figure 1, the clay raw material from Belebey deposit is not homogeneous. The heterogeneity of the clay composition introduces an adjustment in the amount of thinning agent and the value of molding moisture in the process. 


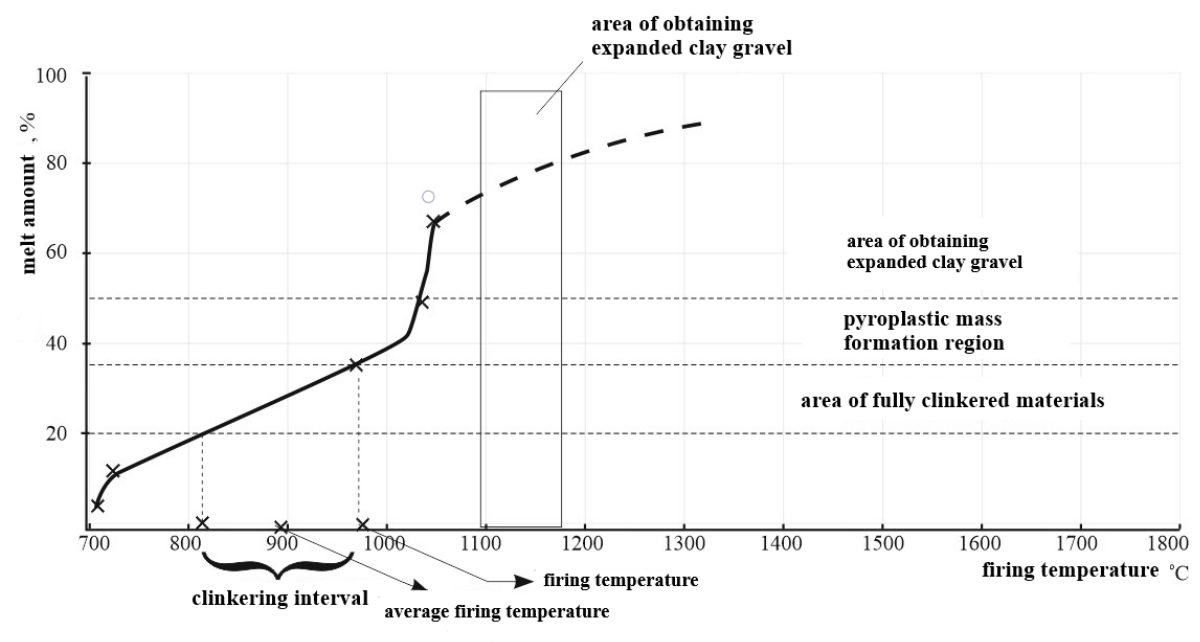

Fig. 2. Clay melt formation dynamics from the Belebey deposit

As follows from the graph (Figure 2), in the clay raw material from Belebey deposit, the amount of $\mathrm{Na}_{2} \mathrm{O}$ and $\mathrm{K}_{2} \mathrm{O}$ fluxing agents is sufficient for liquid clinkering, which ensure melt formation at low temperatures. In the temperature range of $800-1030^{\circ} \mathrm{C}, 20-41 \%$ of the melt is formed, which is enough to produce partially clinkered products, which include ceramic bricks. Also, $\mathrm{Fe}_{2} \mathrm{O}_{3}$ plays the role of fluxing agent, which in the reducing environment transforms into $\mathrm{FeO}$ (that is provided by the presence of organic matter in the raw material). Insoluble part consists of quartz, $\mathrm{CaO}$ and $\mathrm{MgO}$. The fluxing agents excess contributes to a sharp increase in the amount of melt in a short temperature range of $1028-1058^{\circ} \mathrm{C}$, which limits the maximum firing temperature to $1030^{\circ} \mathrm{C}$.

\section{Discussion}

The established calculated maximum firing temperature $\left(1030^{\circ} \mathrm{C}\right)$ is consistent with the recommended firing temperature, obtained by tests. Flashing of products could occur at higher temperatures. The excess of fluxes not included in the melt makes it possible to improve clinkering due to:

- fine grinding of raw materials and the involvement of quartz into the melt;

- introduction of silica-containing additives.

Assessment of the clay raw materials from Belebey deposit by calculation method allowed to:

- determine the maximum firing temperature $-1030^{\circ} \mathrm{C}$;

- determine the firing interval in the range of $900-1030^{\circ} \mathrm{C}$;

- establish the type of additive capable of improving clinkering; silica-containing additive is recommended.

\section{Conclusions}

1. The properties of clay raw materials from Belebey deposit have been studied by standard methods. It is established that raw material refers to: acidic; moderately plastic; 
low-melting; with high content of coloring oxides; moderately plastic; with small and medium carbonate additives.

2. The statistical analysis of the grain size composition of raw material clay and some technological parameters (amount of sand additive and molding moisture) has been performed. The heterogeneity of clay raw materials has been determined, it being reflected in the technological parameters of production and the quality of the products.

3. The non-standard, assessment of clay raw materials from Belebey deposit, carried out with the help of computer program "Assessment showed that " there is a sufficient amount of fluxes for liquid clinkering in the clay raw material, which provide melt formation at low temperatures.

4. The calculation (non-standard) method allowed for the chemical and mineral composition of clay raw materials to determine: the maximum firing temperature; firing interval; and establish the kind of additive that can improve clinkering.

\section{References}

1. Report on geological prospecting of mineral raw materials of Bashkiria, Bashstrom, Ufa KSM complex geodetic party, (1998)

2. V.V. Kuzmin, Materials of the All-Russian XXXI scientific and technical conference: Actual problems of modern construction, Part 1. Building materials and products Ecology, engineering systems, structures and technologies Penza, 42, (2001)

3. V.V. Kuzmin, 58 STC: Research in Architecture, Construction and Environmental Protection, pp. 85-86 (2001)

4. G.I. Kniga, E.N. Vershinina, L.N. Tatskii, $3^{\text {rd }}$ ed., Revised and supplemented by M.: Higher School of Economics, (1985)

5. Technical analysis and control of ceramic production, $2^{\text {nd }}$ ed., additional. Stroyizdat, (1986)

6. V.B. Goryainov, I.V. Pavlov, G.M. Tsvetkova et al .; Ed. V.S. Zarubina, A.P. Krishchenko, Mathematical Statistics Bauman MSTU NE, (2001)

7. V. Borovikov, STATISTICA: the art of data analysis on a computer. For professionals (St. Petersburg, Peter, 2001)

8. N.G. Chumachenko, A.N. Chudin, Certificate of computer program official registration No. 990185. Software package for the assessment of mineral aluminosilicate raw materials, (1999)

9. N.G. Chumachenko, Procedia Engineering 91, pp. 381-385 (2014)

10. N.G. Chumachenko, Building Materials 1, pp. 56-60 (2013) 